\title{
Comprometimento e Justiça Organizacional: Um Estudo de suas Relações com Recompensas Assimétricas
} Organizational Commitment and Justice: A Study
of its Relations With Differentiated Rewards

Comprometimiento y Justicia Organizacional: Un Estudio de Sus Relaciones con Recompensas Asimétricas

José Adauto Ribeiro

Antônio Virgilio

Bittencourt Bastos

Universidade

Federal da Bahia

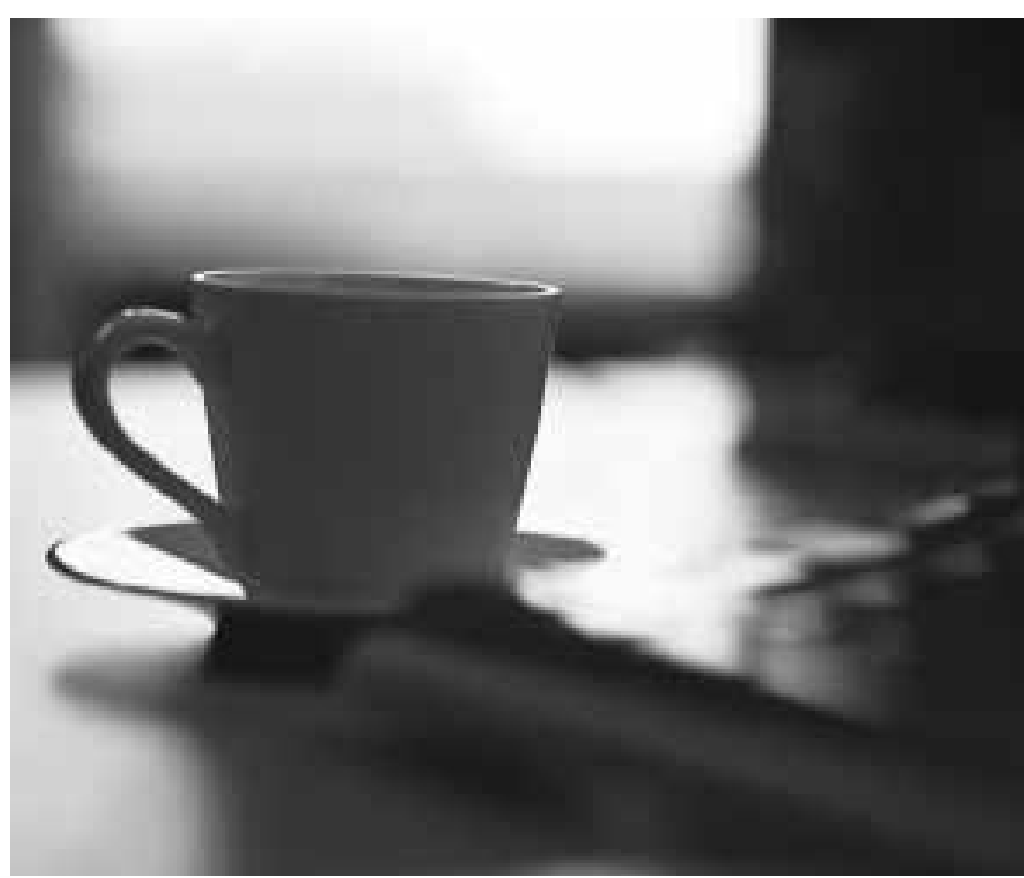


Resumo: Este trabalho teve por propósito investigar as implicações da concessão diferenciada de benefícios e remuneração a dois grupos de funcionários, que exerciam função idêntica em uma mesma empresa, sobre a percepção de justiça distributiva e de comprometimento organizacional. À guisa de suporte teórico, foram explorados os construtos de justiça e comprometimento organizacional. O estudo empírico foi efetuado em uma organização da indústria bancária, e teve por objeto os dados de uma survey realizada junto a uma amostra de 679 pessoas, cindida em dois grupos por distinções contratuais: o pré-98, com 304 indivíduos, e o pós-98, com 379. A diversidade dos dois grupos, com perfis bem distintos e com diferenças significativas de benefícios, se revelou bastante profícua para análises comparativas. Como instrumento de levantamento de dados, foi utilizado um questionário composto de variáveis demográficas, das escalas trifatorial de comprometimento na organização e da dimensão de percepção de justiça distributiva.

Palavras-chave: Comprometimento organizacional. Justiça distributiva. Remuneração e benefícios. Survey.

Abstract: This work aimed at the investigation of the implications of granting differentiated pay and benefits for two groups of clerks who exerted similar functions in the same company on the perception of distributive justice and organizational commitment. The constructs of justice and organizational commitment were explored as theoretical support. The empirical study was carried out in an organization of the banking industry and was the object data from a survey conducted with a sample of 679 people, split into two groups by contractual distinctions: the pre-98, with 304 individuals, and post-98, with 379 people. The diversity of the two groups with very different profiles and significant differences in the benefits has proved very useful for comparative analysis. A questionnaire composed of demographic variables and trifatorial scales of commitment in the organization and the scale of perception of distributive justice was used as a tool of data survey.

Keywords: Organizational commitment. Distributive justice. Pay and benefits. Survey.

Resumen: Este trabajo tuvo por propósito investigar las implicaciones de la concesión diferenciada de beneficios y remuneración a dos grupos de empleados, que ejercían función idéntica en una misma empresa, sobre la percepción de justicia distributiva y de comprometimiento organizacional. A modo de soporte teórico, fueron explotados los constructos de justicia y comprometimiento organizacional. El estudio empírico fue efectuado en una organización de la industria bancaria, y tuvo por objeto los datos de una survey realizada junto a una muestra de 679 personas, escindida en dos grupos por distinciones contractuales: el pre-98, con 304 individuos, y el post-98, con 379. La diversidad de los dos grupos, con perfiles bien distintos y con diferencias significativas de beneficios, se reveló bastante proficua para análisis comparativos. Como instrumento de levantamiento de datos, fue utilizado un cuestionario compuesto de variables demográficas, de las escalas trifactoriales de comprometimiento en la organización y de la dimensión de percepción de justicia distributiva.

Palabras clave: Comprometimiento organizacional. Justicia distributiva. Remuneración y beneficios. Survey.

A instabilidade profissional e empresarial recrudesceu no alvorecer dos anos noventa. Na emergência da revolução microeletrônica e comunicacional, o ideal no mercado converteu-se na habilidade de interpretar tendências para a conquista de diferenciação como estratégia de enfrentamento ao padrão de seleção natural vigente, estabelecendo um novo paradigma de desempenho: a precisão interpretativa da realidade, ou seja, quanto menor for a defasagem entre a percepção do ambiente e sua mais recente configuração, maiores são as chances de sucesso. Identificar as mudanças, ainda na fase embrionária, e adaptar a organização para explorar as oportunidades emergentes e mitigar as ameaças é crucial para o progresso nos negócios. É sobre o comprometimento e seu valor como atributo organizacional em cenário de mudança que se procura encetar a apresentação desse liame psicológico.

Sobre a realidade da nova base técnica da produção dinâmica, flexível e convergente, Drucker (2006) afirma que o fim das divisas tecnológicas derrubou os muros que demarcavam as indústrias. Antes, as empresas competiam dentro de um mesmo setor. Bastava conhecer bem a tecnologia da própria área para prosperar. Hoje o aço compete não apenas com o alumínio mas também com o plástico de companhias 
petrolíferas e químicas. As tecnologias atuais se cruzam com frequência, e podem flanar sobre campos antes insondáveis. A premissa que se deduz é que a necessidade é única, mas o meio de satisfazê-la é diversificado. Os novos processos produtivos que emergem da mobilidade e da convergência tecnológica, da mundialização do mercado, impõem ao trabalhador postura protagonista no campo das decisões. Para o êxito competitivo da empresa, é essencial que seus empregados assimilem os redirecionamentos estratégicos, visando a antecipar os movimentos dos stakeholders. Para Malvezzi (1994), o desafio maior é o de preparar as pessoas para enfrentar a realidade volátil, que exige adaptações incrementais e, eventualmente, revisões radicais.

O ambiente organizacional, segundo Drucker, modifica-se com velocidade excepcional, e a globalização é o seu ápice. Para sobreviver, as organizações precisam criar novas estruturas que permitam lidar com as turbulências causadas pelas flutuações do mercado, pelos avanços tecnológicos e, sobretudo, precisam formar equipes de pessoas comprometidas com seus objetivos e motivadas para aprender novas formas de fazer as coisas, para mudar hábitos e até mesmo valores. Sobre as descontinuidades de tendências e a inevitável integração das empresas com seus ambientes, Ansoff e McDonnell (1993, p. 549) acreditam que a flexibilidade organizacional para reagir a eventos inesperados se transformará em uma preocupação básica da administração estratégica.

É da natureza das empresas o afã de ampliar vendas, participação no mercado e obter resultados, visando a acumular riqueza e a garantir a sobrevivência. $\mathrm{Na}$ atualidade, por conta dos avanços dos meios de comunicação, dos transportes e da tecnologia da informação, as fronteiras dos mercados estão se movendo na direção dos limites globais. E sabe-se que o ambiente continua competitivo e que sua intensidade é crescente, mas não se conhece mais quem são os reais competidores e onde eles estão.

No ambiente hostil das disputas por territórios mercadológicos, onde as empresas são sempre contestadas, avançar sobre o espaço de seus concorrentes e defender o já conquistado é uma questão vital. É consenso no meio empresarial que a identificação, a lealdade e o envolvimento das pessoas são a base para a formação de um grupo coeso e sinérgico, que se movimenta na mesma direção, com pleno emprego de suas competências e orientados por uma visão inspiradora. O comprometimento é uma das forças relevantes que compõe a vitalidade competitiva da organização.

As empresas estão percebendo que as vantagens competitivas na área de tecnologia, gestão, processos e produtos estão ficando, progressivamente, mais efêmeras, pois a concorrência tem demonstrado capacidade de identificar e mimetizar, com celeridade crescente, os diferenciais das empresas pioneiras. No mundo do trabalho, o comprometimento é o atributo único e exclusivo de uma equipe de determinada organização, que não pode ser clonado por outros competidores e que propicia constância e vigor ao seu ânimo competitivo.

Embora sua relevância seja reconhecida, o comprometimento organizacional não é uma panacéia, mas, inequivocamente, uma das qualidades importantes que está presente nos times das empresas bem sucedidas, já que uma equipe de pessoas comprometidas tende a ser mais leal, a assumir conduta diligente, a expressar interesse genuíno sobre os rumos da organização, a dedicar-lhe esforços extras e a contribuir voluntariamente com o seu desenvolvimento. Por isso, todas as empresas aspiram ter empregados comprometidos com seus valores, crenças, estratégia e resultados. A expectativa é tão elevada que algumas 
empresas esperam que eles, na sua práxis diária, pensem e ajam como se fossem os donos ou os controladores da companhia.

Diante da evidência do valor do vínculo indivíduo/organização, a questão que se coloca é a seguinte: como desenvolver relações e criar um clima de trabalho favorável à geração de comprometimento consistente? A resposta a essa pergunta exige um saber nada trivial. O cerne da complexidade está na multiplicidade de percepções e de respostas das pessoas a um mesmo estímulo, no contexto do trabalho. A idiossincrasia, atributo ontológico do indivíduo, que consigna sua singularidade e ao mesmo tempo proclama sua diversidade como grupo, torna as pessoas mais enigmáticas, e converte o estudo e a gestão das relações na organização em experiência instigante e desafiadora. A pesquisa dos antecedentes, conforme Meyer e Allen (1997), produz conhecimento útil para o gerenciamento do comprometimento, pois estuda o processo de desenvolvimento desse vínculo.

O reconhecimento crescente da relevância do comprometimento como facilitador do processo de mudanças internas, como um amálgama de esforços em prol da capacidade de adaptação e da competitividade organizacional, que contribui para a sustentabilidade dos negócios, colocou esse fenômeno atitudinal e comportamental no centro das preocupações estratégicas das organizações. No ambiente acadêmico, tem fomentado empreendimentos de novas pesquisas e concorrido para estabelecer esse domínio como pujante área de estudo (Rego \& Souto, 2004).

Com relação ao antecedente remuneração e benefício, este estudo depara-se com um critério de distribuição atípico. Não é corriqueiro, no mercado de trabalho, o fato de a mesma empresa ter dois grupos de empregados pertencentes à mesma carreira que ocupam cargo idêntico e exercem função igual, identificados e distinguidos por contratos com recompensas diferentes, sendo um mais amplo que o outro. Esse fato, além de inusitado, constitui uma oportunidade para se estudar quais as consequências e os impactos gerados sobre a percepção de justiça distributiva e sobre o comprometimento organizacional verificados nesses dois segmentos de funcionários. Este estudo oferece uma contribuição relevante para a discussão do desenvolvimento do comprometimento, tendo por antecedente a justiça organizacional em uma circunstância de percepção de equidade de recompensa exacerbada por dissimilitude contratual. No cerne desta pesquisa, está a questão da diversidade de contratos, que é característica do mundo do trabalho contemporâneo e constitui tema candente no debate das relações no ambiente corporativo.

\section{Fundamentação teórica}

Em razão da pesquisa, este estudo tem por base conceitual dois fenômenos organizacionais: o comprometimento e a percepção de justiça, temas que estruturam o presente segmento do trabalho.

De acordo com Gama (1997), no campo dos estudos das organizações, o comprometimento organizacional é um enlace psicológico desenvolvido pelo indivíduo a partir de suas percepções e de suas relações com os elementos ambientais do trabalho. As bases são elementos centrais, considerados do ponto de vista do indivíduo, para a definição de conceitos, tipologias e para a aplicação de escalas de mensuração de intensidade do comprometimento. Trata-se de diferentes estruturas disposicionais sobre as quais os vínculos são forjados e sustentados. Dentre as bases de comprometimento propostas, as mais aceitas e reconhecidas nas pesquisas 
são: afetiva, normativa e instrumental. Embora essas três dimensões façam parte do mesmo fenômeno, cada uma delas tem uma dinâmica própria, reage aos antecedentes e se relaciona com os consequentes de modo diferenciado, registrando intensidades distintas e manifestando certa autonomia. Essa diversidade de bases é congruente com uma visão multidimensional do construto, o que permite o estudo de como tais bases se combinam formando perfis de comprometimento organizacional.

Base afetiva - O comprometimento de base afetiva foi estruturado a partir do trabalho de Mowday, Steers e Porter (1979). Segundo Medeiros et al. (2002), embora já houvesse a linha de pesquisa que considerava o comprometimento organizacional expressão do comportamento do empregado no trabalho, os autores imprimiram aos seus estudos uma abordagem atitudinal.

Para Barbosa e Faria (2000), o enfoque atitudinal sustenta que o comprometimento decorre da disposição individual, ativada pela interação de elementos contextuais. Os pesquisadores Mowday et al (1979) utilizaram definição que preconizava o comprometimento como uma forte relação de identificação do indivíduo com determinada organização, que pode ser caracterizada por três fatores alusivos ao seu alvo: estar disposto a exercer considerável esforço, forte crença e aceitação de objetivos e valores e forte desejo de se manter membro.

Segundo Bandeira et al. (2000), nessa abordagem, o indivíduo assume uma postura ativa, em que se parte da suposição de que ele deseja dar algo de si para a empresa. $\mathrm{O}$ comprometimento afetivo, então, representa um elo mais intenso com a organização, considerando que esse tipo emerge e se nutre dos sentimentos do empregado, da aceitação de crenças, da identificação e da assimilação de valores. Esses elementos não configuram variáveis com trajetória estocástica e tendem a ser mais estáveis, menos sujeitos às mudanças situacionais e conjunturais, portanto, conformam uma base mais sólida e duradoura.

Base instrumental - Conforme Bastos (1994), outras denominações também são utilizadas, como side bets, calculativo, continuance ou continuação. A base instrumental teve como origem os estudos de Becker (1960), que definiu a vertente instrumental como tendência do indivíduo de se engajar em linhas ou cursos consistentes de ação, permanecendo na empresa devido aos custos e sacrifícios associados a sua saída, que seriam as trocas laterais. Os subcomponentes que formam a faceta instrumental são a avaliação dos custos em deixar a organização, cuja perspectiva é interna, e a avaliação das alternativas oferecidas pelo mercado de trabalho, voltado para o ambiente externo.

O comprometimento instrumental é um produto da comparação de relações racionais. Pondera-se o custo/benefício de ficar com o de ingressar em outra organização. $\mathrm{O}$ julgamento de ficar é fortemente contaminado pela sensação de segurança, tendo em vista que as informações consideradas se referem ao ambiente e às relações conhecidas e vivenciadas. A avaliação da alternativa de sair, por seu turno, é influenciada pela incerteza, à medida que as relações e o ambiente sopesados são desconhecidos. Nessa equação, a incerteza gera um custo adicional, sob a forma de risco de insucesso. Por essa razão, o indivíduo tende a demandar, para ingressar em nova organização, benefícios expressivamente maiores como forma de compensação para o risco assumido.

As organizações são sistemas influenciados fortemente pela racionalidade, e suas decisões sobre investimentos são orientadas por relações custo/beneficio da unidade analisada, inclusive de postos 
de trabalho. Nesse caso, os empregados que expressassem comprometimento instrumental predominante estariam, guiados pela lógica da troca, da reciprocidade e da equidade, procurando sintonizar as relações no mesmo padrão de vínculo, equiparando o tratamento mútuo e evitando desenvolver afetividade com quem (a organização) se envolve de forma calculista e transacional. Assim, hipoteticamente, teríamos o terceiro subcomponente instrumental: a reciprocidade.

Base normativa - Embora alguns autores façam referências ao trabalho de Kanter, de 1968, o primeiro pesquisador a conceituar efetivamente o comprometimento normativo foi Wiener, (1982), que o concebeu como a totalidade das pressões normativas internalizadas para agir consistentemente em sintonia com os objetivos e interesses organizacionais. Para Medeiros et al. (2002), essas pressões quase sempre têm origem na cultura da organização, que impõe um modo de ação e de comportamento na empresa. Conforme Wiener, a visão normativa sugere um foco centrado no controle instrucional, como normas, regulamentos ou uma missão forte e disseminada.

Cabe frisar que cultura e estratégia desempenham papel central no elo normativo, sendo os seus principais indutores. Atuam sobre os indivíduos por identificação e sob a forma coercitiva, as quais se manifestam pela ação de normas, expressas ou não, por padrões de conduta, políticas, diretrizes, valores, metas e resultados, que comunicam o que é adequado fazer e as expectativas para o futuro. A identificação se dá pela congruência entre os elementos culturais da organização e os valores que o empregado traz de sua formação e pelos objetivos que projeta na relação com a organização.

As concepções das bases de comprometimento prosperaram a partir da refutação da ideia de que esse vínculo seria um construto unidimensional. Coube a Meyer e Allen (1997) o mérito de engendrar um modelo integrativo que representasse a operacionalização simultânea e articulada das abordagens afetiva, de Mowday et al. (1979), instrumental, de Becker (1960), e normativa, de Wiener (1982), nos processos de estudo empírico do comprometimento. O sucesso desse artefato teórico se verificou com a crescente adesão e aplicação por pesquisadores até alcançar o status de modelo tridimensional de comprometimento mais aplicado no ambiente acadêmico.

Bandeira et al. (2000) assinalam que as definições das dimensões propostas pelos autores consideram a natureza de estado psicológico do vínculo do indivíduo com a organização. Com base nas diferenças da constituição desse estado é que Meyer e Allen (1997) preconizaram o modelo ternário de componentes: afetivo, instrumental e normativo, cujos conceitos foram assim definidos: empregados com forte comprometimento afetivo permanecem na organização porque assim o querem; aqueles cuja ligação está ancorada na base instrumental continuam empregados porque precisam; empregados com alto grau de comprometimento normativo sentem que têm que permanecer na organização, imbuídos de um sentimento de dever.

Embora o modelo de Meyer e Allen venha desfrutando da reputação de majoritária aceitação e aplicação, não passou incólume pelas avaliações críticas, que apontaram no estudo algumas inconsistências. A avaliação de correlação entre as dimensões afetiva e normativa, por exemplo, tem registrado índices tão elevados que apontam uma inquietante aposição ou redundância entre essas duas dimensões. Esses resultados têm propiciado oportunidade para alguns autores questionarem a autonomia das 
Meyer et al. (2002) afirmaram que, notavelmente, a correlação entre as escalas afetiva e normativa tem sido muito forte escalas ou para propor a junção dessas duas dimensões. Meyer et al. (2002) afirmaram que, notavelmente, a correlação entre as escalas afetiva e normativa tem sido muito forte. No conjunto, afirmam os autores, esses resultados sugerem que mais estudos são necessários para compreender o fator normativo, o seu desenvolvimento e o seu poder preditivo de comportamento.

Sobre a avaliação do comprometimento em diferentes lugares e países, cabe salientar que a ocorrência desse fenômeno não é autóctone, e sua universalização tem sido promovida pela globalização mediante a disseminação de padrões de perfis e de conduta profissional, homogeneizando atitudes e comportamentos na organização. Entretanto, as culturas locais estabelecem nuances na configuração das relações de trabalho entre o indivíduo e as variáveis contextuais, propiciando campo para estudos comparativos de comprometimento.

Os antecedentes do comprometimento organizacional - Podem ser compreendidos como variáveis que, sinergicamente articulados e em interação com as expectativas e a percepção do indivíduo, eliciam o comprometimento. Essas variáveis têm mais valor no mundo das percepções do que na realidade dos fatos, e possuem um caráter de continuidade em oposição à ação pontual e estanque. Quando deixam de ser captados pelo radar de percepção das pessoas, não importa se continuam a existir ou não, perdem o seu efeito influenciador sobre atitude e comportamento. Nesse caso, a comunicação interna, ou endomarketing, ganha relevo estratégico, e pode constituir ferramenta eficaz para a divulgação dos programas de vantagens e benefícios, inclusive comparada com práticas de $\mathrm{RH}$ de empresas do setor.

Bastos (1994) aponta um conjunto de ações organizacionais que estimulam o comprometimento: recrutamento e seleção, treinamento e qualificação, política de reconhecimento, sistema de recompensa e liderança participativa. Walton (como citado em Vroom, 1997) também cita um rol de práticas que podem gerar vínculos mais intensos: redução de níveis hierárquicos, maior autonomia, integração de atividades, oportunidades de carreira, disponibilidade de informação, estímulo à participação, maior responsabilidade, atividade mais flexível e percepção de justiça.

Vários autores (Blau, 1987; Kidron 1978, como citado em Mathieu e Zajac, 1990) têm estudado a influência axiológica, e suas conclusões revelam que, na vertente dos valores do trabalho, os resultados são convergentes e assinalam que o comprometimento é superior para os praticantes da ética protestante do trabalho. Arnold e Davey (como citado em Tamayo et. al., 2001), em estudo longitudinal, observaram que a natureza do trabalho, a carreira e as recompensas intrínsecas e extrínsecas são preditores significativos do comprometimento organizacional. As correlações entre as variáveis de características organizacionais (tamanho, centralização, formalização) e comprometimento foram neutras (Mayer et al., 2002).

Os consequentes - Se o comprometimento for considerado um produto, os consequentes podem ser tomados como seus subprodutos ou resultados adjacentes gerados por sua ocorrência. Os consequentes são externalidades da conduta do indivíduo decorrentes do tipo e da intensidade do comprometimento que ele desenvolve no contexto do trabalho, por exemplo: o desempenho observável, os resultados realizados, a frequência, a pontualidade, a intenção de deixar a empresa, as saídas efetivas, as ações extrapapel, etc. 
Sobre a dedicação no trabalho, Rego e Souto (2004) avaliam que é mais provável que os indivíduos afetivamente comprometidos estejam motivados para contribuir mais vigorosamente para a organização com desempenho superior. Os indivíduos normativamente envolvidos tendem a contribuir positivamente para a organização. Todavia, o sentimento de obrigação não suscita o mesmo entusiasmo e o envolvimento que resultam da faceta afetiva.

Meyer et al. (2002), visando a estudar a consistência do construto trifatorial de comprometimento de Meyer e Allen (1997) e suas relações, realizaram meta-análise envolvendo pesquisa de 155 trabalhos publicados entre 1985 e 2000. Eles concluíram que os resultados, em geral, suportaram o modelo e apoiaram a continuidade da utilização de suas medidas escalares. O Quadro 1 retrata as relações entre o comprometimento e os antecedentes, consequentes e correlatos.

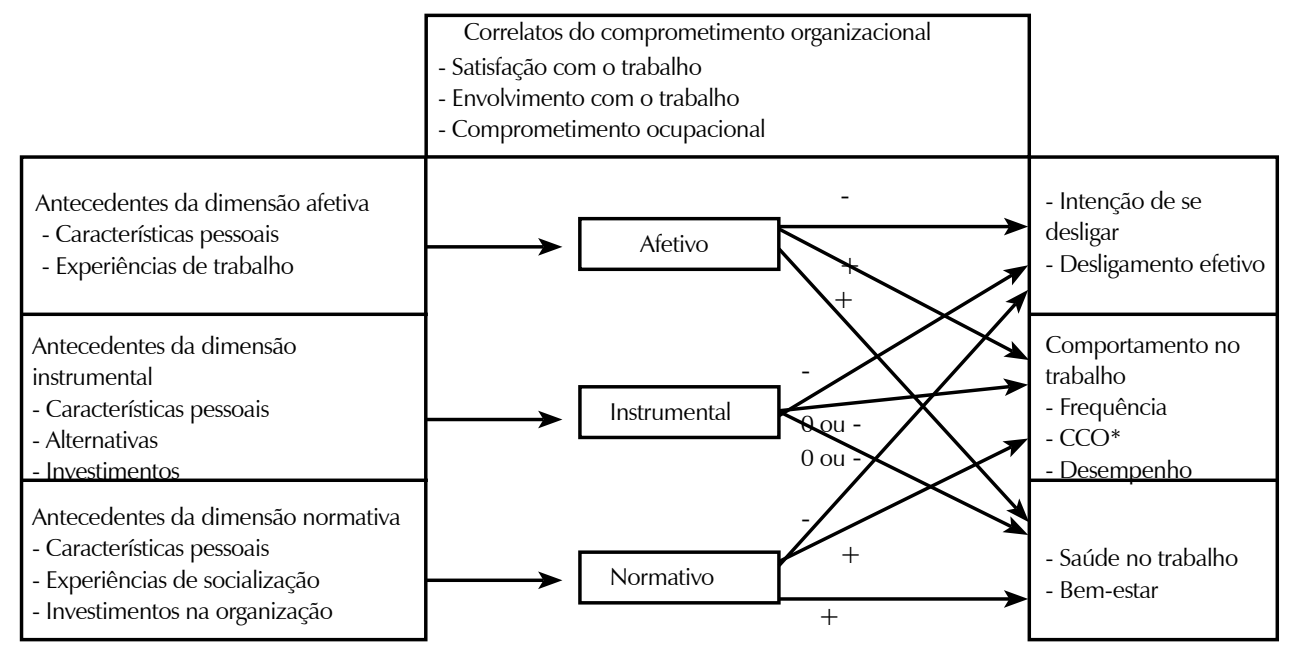

Quadro 1. O modelo tridimensional de Meyer e Allen e seus antecedentes, correlatos e consequentes.

Fonte: Traduzido e adaptado de Meyer et al. (2002)

* comportamento de cidadania organizacional

Neste estudo, procurou-se investigar a relação entre recompensa e percepção de justiça bem como a interação desses dois fatores, na condição de antecedentes, com comprometimento organizacional; portanto, a percepção de justiça, que, assim como o comprometimento, constitui um construto tridimensional, serviu de base teórica para este trabalho, e, a seguir, recebe uma breve descrição conceitual dos resultados de pesquisas precedentes.

Percepção de justiça - Rawls (1971), ao publicar Uma teoria da justiça, manejando o conceito de contrato social e os pressupostos do relacionamento, calcados em acordo e cooperação entre indivíduos, faz uma abordagem social de justiça, entendida como estrutura básica da sociedade, e apresenta uma noção de organização institucional. Desde então, o conceito de justiça passa a ser explorado mais intensivamente por outras disciplinas. A Psicologia social, que tem como objeto de estudo o comportamento humano em sociedade e as relações funcionais entre o ambiente e os processos psicológicos (Asch 1977, como citado em Palazolli, 2000), utiliza o conceito para estudar as interações entre pessoa e organização.

A justiça organizacional é resultado das trocas sociais e contratuais, no contexto do trabalho, e se verifica no campo das percepções. O indivíduo julga o tratamento recebido como mais ou 
menos justo, conforme a avaliação que ele faz entre suas expectativas e as informações e os sentidos que capta do ambiente organizacional. Portanto, a percepção de justiça é um construto impregnado pela subjetividade do indivíduo, à medida que se realiza no seu íntimo, e é eliciado a partir de sua história de vida, de suas expectativas e das leituras que faz do mundo exterior. Por outro lado, a intangibilidade do fenômeno não compromete seu estudo, conforme o resultado da pesquisa de Lewin (1935, como citado em Mendonça et al., 2004), a qual avaliou as percepções da pessoa sobre o mundo que a cerca como melhor insumo, para compreensão de seu comportamento, do que as descrições objetivas dos estímulos ambientais. A investigação da justiça organizacional se desdobra em três dimensões, que podem ser estudadas de maneira independente ou articulada: distributiva, procedimental e interacional (Omar, 2006).

Percepção de justiça distributiva - Coube a Homans (1958) o pioneirismo de introduzir o termo justiça distributiva no campo dos estudos organizacionais. Com base na teoria da equidade, de Adams, conceituou que a relação é percebida como justa quando a distribuição é proporcional à contribuição de cada um em determinado grupo social. Mendonça et al. (2004) comentam que essa regra básica prescreve que os indivíduos formulam suas expectativas de retribuição em razão de seus investimentos, procurando ser recompensados. Quanto maior o investimento, mais o indivíduo espera como recompensa. E, quanto maior a recompensa, mais o trabalhador é exigido em custos e sacrifícios. A lógica está na proporcionalidade entre contribuição e recompensa.

Outra faceta importante desse construto é a comparação com o outro feita pelo indivíduo. Nesse sentido, ainda sob a influência da teoria da equidade e apoiado no preceito aristotélico de que o justo é o proporcional, um dos princípios dessa dimensão postula que uma dada distribuição de resultados é percebida como equitativa por um determinado indivíduo se a razão entre seus investimentos ou esforços realizados (numerador) e as recompensas ou resultados obtidos (denominador) for igual à razão entre os mesmos termos de um outro com quem a pessoa se compara (Adams 1965, como citado em Coradi, 1985). Os investimentos podem ser: o próprio trabalho, a dedicação autopercebida, a capacitação, o tempo de relação, o sacrifício da qualidade de vida, etc. As recompensas percebidas constituem: salário, sensação de suporte e segurança, reconhecimento ou status e benefícios. Quando os rácios são desiguais, ocorre a iniquidade: favorável, quando a pessoa é super-recompensada, e desfavorável, quando é sub-recompensada. A percepção de iniquidade gera tensão, e motiva a pessoa a buscar a equidade ou a diminuir a iniquidade.

Apesar do inegável valor heurístico da teoria da equidade, haja vista a pletora de pesquisas experimentais que se sucederam à sua publicação, esse conceito, de acordo com Assmar, Ferreira e Souto (2005), apresenta lacunas que propiciaram espaço para a identificação de outras concepções.

Percepção de justiça procedimental - A restrição do poder explicativo para as reações negativas às injustiças percebidas reside na concentração dos fatores limitados à distribuição de resultados. Destarte, ficou evidente a incompletude da justiça distributiva para dar conta do fenômeno. A justiça procedimental ou processual vem suprir essa lacuna, pois considera os critérios e as condições inerentes aos processos de decisão sobre a definição e a alocação dos resultados e as recompensas. 
Em consonância com as propostas de Rawls e utilizando a mesma denominação, Thibaut e Walster (1975, como citado em Gomide Jr., 1999) introduziram, no âmbito da Psicologia social, o termo justiça dos procedimentos. A justiça processual parte do princípio de que os procedimentos têm por finalidade regular trocas cooperativas, garantindo coerência, e minimizar os efeitos dos conflitos intra ou intergrupal. A justiça procedimental focaliza o processo que se verifica na tomada de decisão e na implementação da distribuição de resultado (Rego \& Souto, 2004). Seu objeto de análise são os meios utilizados para a consecução dos fins alcançados, por isso, é conhecida como a justiça dos meios. Quando os procedimentos são percebidos como justos, sobretudo se forem participativos, os indivíduos se tornam mais lenientes a resultado desfavorável, pois tendem a admitir mais a sua responsabilidade pelo retorno obtido (Thibaut 1975, como citado em Siqueira, 1995).

Percepção de justiça interacional - Nas pesquisas empíricas do final dos anos 80, verificou-se que a interação social e a comunicação da decisão são importantes para a sensibilidade dos indivíduos em relação à justiça. A dimensão interacional focaliza a qualidade das relações sociais que ocorrem entre o indivíduo afetado por decisões e a administração. Omar (2006) assinala que a justiça interacional está associada à qualidade da relação interpessoal entre os gestores e os empregados atingidos por suas decisões, ao modo como os decisores se comportam durante os contatos com os subordinados, sobretudo quanto ao tratamento que envolva respeito, dignidade, justificativa coerente, transparência e fornecimento de informações.

O conceito de justiça interacional é o mais polêmico e passa por altercações, no debate acadêmico, em dois flancos: o que contesta sua autonomia e o que propõe sua cisão. Nessa senda revisionista, o estudo de validação do construto realizado por Colquitt (2001) reportou sólidas evidências em favor do modelo, proposto por Greenberg, em 1993, com taxonomia de quatro classes de justiça. Em função dessa tipologia tetradimensional, os elementos sociais presentes na faceta interacional se desdobraram nas chamadas justiça interpessoal e informacional. A primeira refere-se ao grau de sensibilidade social do gestor quanto ao tratamento digno e respeitoso dirigido às pessoas afetadas pelas decisões e pelos procedimentos de distribuição; a segunda é alusiva às informações e às explicações sobre as decisões tomadas quanto a clareza, oportunidade e abrangência.

Omar confirma que, desde o seu surgimento como dimensão autônoma, a justiça interacional tem suscitado controvérsia. Além de seu desmembramento, questiona-se sua distinção e autonomia em relação à justiça procedimental. Há, portanto, necessidade de realização de novas pesquisas para elucidar essas questões. Ainda assim, o conjunto de publicações na área ratifica, mormente, a justiça organizacional como construto trifatorial, conforme quadro conceitual a seguir:

\begin{tabular}{llll}
\hline Dimensão & Descrição conceitual & Definição & Foco \\
\hline Distributiva & $\begin{array}{l}\text { Avalia o tratamento justo através da proporção } \\
\text { entre seus esforços e os resultados distribuídos e } \\
\text { pela comparação dessa relação com os seus pares }\end{array}$ & A justiça finalística & Resultados \\
\hline $\begin{array}{l}\text { Processual ou } \\
\text { procedimental }\end{array}$ & $\begin{array}{l}\text { Avalia o tratamento justo considerando o processo } \\
\text { de elaboração de critérios de avaliação, de } \\
\text { reconhecimento e de distribuição de resultados }\end{array}$ & A justiça dos meios & Processo \\
\hline Interacional & $\begin{array}{l}\text { Avalia o tratamento justo ponderando os contatos } \\
\text { interpessoais dos decisores no sentido do respeito, } \\
\text { da dignidade e da disponibilidade de informações } \\
\text { claras, precisas, transparentes e oportunas }\end{array}$ & A justiça do diálogo & Comunicação \\
\hline
\end{tabular}

Quadro 2. Síntese conceitual dos três fatores de justiça organizacional. 
Os antecedentes e os consequentes da justiça organizacional -Segundo Assmar et al. (2005), os estudos dos antecedentes constituem um esforço para ampliar e aprofundar o conhecimento sobre o comportamento do indivíduo nas organizações. Nesse sentido, a pesquisa sobre justiça tem se estendido a diversos contextos organizacionais em busca de elementos-chave que possam eliciar avaliações de justiça. Sob essa ótica, os pesquisadores têm procurado identificar os fatores que influenciam os julgamentos de justiça distributiva, processual e interacional.

De acordo com as autoras, os resultados nos diversos estudos empíricos documentam que a cultura erigida nos sistemas de gestão, nas políticas e práticas, as mudanças organizacionais, o comportamento dos lideres, a organização e a distribuição do trabalho, os programas de treinamento, os sistemas de recompensa, recrutamento e seleção, a avaliação de desempenho profissional e os processos disciplinares podem ser considerados antecedentes relevantes de percepção de justiça e evidenciam o alcance do valor da justiça no trabalho e sua estreita conexão com a vida organizacional.

O escopo da investigação sobre os principais consequentes da justiça organizacional engloba as respostas atitudinais e comportamentais orientadas para um resultado específico ou para o trabalho, seja em relação ao supervisor, seja em relação à organização (Omar, 2006). Como exemplo, citam-se as possíveis reações ao tratamento percebido como injusto: insatisfação, resistências a decisões gerenciais, atitudes antissociais, baixo desempenho, turnover, absenteísmo, menos comportamento extrapapel e aumento de críticas à organização.

Da Silva et al. (2004), no trabalho sobre correlação entre justiça organizacional e a síndrome de Burnout, evidenciaram o nexo entre percepção de justiça e estresse ocupacional. Em outro trabalho, Rego e
Souto (2004) comentam que os indivíduos, quando experimentam percepções de justiça procedimental ou interacional elevadas, desenvolvem comprometimento afetivo e normativo. Com relação à faceta instrumental, a percepção de justiça tem correlação neutra.

Colquitt et al. (2001), em meta-análise de 183 estudos sobre justiça no trabalho, investigaram as correlações com satisfação no trabalho, cidadania organizacional e desempenho. Foi identificada alta correlação entre a satisfação no trabalho e as três dimensões; comportamento de cidadania teve correlação moderada com justiça distributiva e processual, e a correlação com desempenho organizacional foi elevada em relação à justiça processual, moderada com a distributiva e fraca em alusão ao fator interacional.

\section{Método}

O presente estudo tem como objetivo identificar as possíveis consequências sobre o comprometimento organizacional e a percepção de justiça distributiva causadas pela instituição de remuneração e benefícios diferenciados entre dois grupos de funcionários da mesma empresa bancária, caracterizados pela data de contratação, antes e depois de 1998, e verificar as relações entre as variáveis demográficas, comprometimento e justiça distributiva. A questão primordial deste estudo decorre da interação de remuneração e benefícios, justiça distributiva e comprometimento organizacional. Com base na meta-análise de Meyer et al. (2002), formularam-se as hipóteses: H1 - Remuneração e benefícios inferiores, concedido aos participantes do grupo pós-98, relaciona-se negativamente com justiça distributiva e com comprometimento organizacional, gerando médias inferiores em relação ao grupo pré-98; H2 - Remuneração e benefícios superiores, concedido aos participantes do grupo pré-98, relaciona-se 
positivamente com justiça distributiva e com comprometimento organizacional, gerando médias superiores em relação ao grupo pós-98; H3 - Há correlação positiva entre justiça distributiva e as dimensões de comprometimento, sendo as mais intensas com os elos afetivo e instrumental, nessa ordem, e a menos vigorosa, com o normativo.

Como referência à formulação do modelo aplicado à pesquisa, conforme o Quadro 3, foram utilizados o quadro elaborado por Mathieu e Zajac (1990), que propõe a identificação e a classificação dos antecedentes de comprometimento, e a meta-análise de Meyer et al. (2002), especialmente o sumário das relações tendenciais das variáveis antecedentes, correlatos e consequentes com as três dimensões de comprometimento.

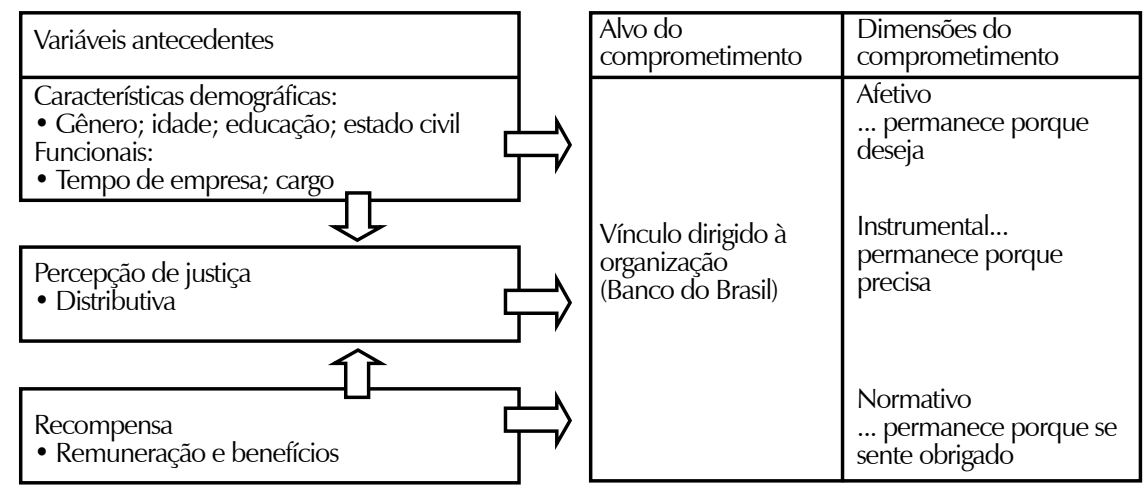

Quadro 3. O modelo teórico aplicado à pesquisa empírica.

O modelo proposto tem por objetivo servir de esquema para verificação das possíveis relações das variáveis antecedentes com justiça distributiva e a tipologia trifatorial de comprometimento de Meyer e Allen (1997). A pesquisa foi realizada no Banco do Brasil, considerado o maior banco da América Latina. Presente em todo o Brasil e no exterior, essa corporação tem tradição secular.

A Resolução no. 09, de 08.10.1996, publicada pelo Conselho de Coordenação e Controle das Empresas Estatais - CCE, obrigou suas controladas a limitar a concessão de remuneração e benefícios ao mínimo previsto na Consolidação das Leis do Trabalho (CLT). Adaptando-se à Resolução, o Banco manteve inalteradas as condições de remuneração e benefícios, anteriores à norma, dos empregados já contratados. Para os contratados a partir de 1998, criou uma nova carreira, com critério salarial específico e benefícios restritos à CLT, o que provocou uma clivagem no quadro funcional, cindindo-o em dois grupos: os pré-98 e os pós-98. Atualmente, o grupo pós-98 já representa mais da metade de todos os 86.000 empregados da empresa.

Neste trabalho, adotou-se a abordagem descritiva e de recorte transversal em relação ao objeto de estudo. Como estratégia de levantamento de dados, utilizou-se a modalidade survey. Quanto aos procedimentos, a investigação caracterizou-se como estudo de campo, à medida que os dados foram levantados diretamente na organização estudada. A população foi composta pelos 1804 funcionários que trabalhavam nas 330 agências do Banco, localizadas no Estado da Bahia, e que ocupavam os cargos de escriturário e caixa. O erro amostral estimado foi estabelecido em 4\%. A partir da população, chegou-se a uma amostra mínima admissível de 464 indivíduos. Os questionários foram enviados a todos os indivíduos da população. No retorno, foram recebidos 
679 questionários respondidos, sendo 304 de funcionários pré-98 e 379, de pós-98. A devolução alcançou número suficiente para dar consistência à análise estatística.

Como instrumento de levantamento de dados primários, foi utilizado questionário de perguntas no formato likert com 5 pontos. Para os dados sobre comprometimento organizacional, foi utilizada a escala tridimensional, de Meyer e Allen (1997), composta por 18 itens. Para justiça distributiva, utilizou-se escala com 6 itens, de Siqueira et al. (1996). Esses instrumentos foram validados no contexto cultural brasileiro por diversos autores.

Além das análises fatoriais, na avaliação das escalas, utilizou-se o coeficiente de alpha de Cronbach, cujos índices foram satisfatórios em termos de consistência interna e nível de confiabilidade. Para registro, processamento e análise de dados, foi usado o programa SPSS, versão 14. Os procedimentos estatísticos realizados foram: estatística descritiva, alpha de Cronbach, análise de correlação de Pearson e análise de regressão.

\section{Resultados e discussão}

Analisando os subgrupos pré-98 e do pós-98 quanto às características demográficas e funcionais, verifica-se que, na variável gênero, não houve diferença marcante, com 40,8\% de mulheres no pré-98 e 42,1\%, no pós-98. O grupo pré-98 caracterizou-se por forte concentração de indivíduos nas faixas de idade superior a 40 anos, com 84\% de participação. A distribuição do pós-98 registrou disposição inversa, com $88 \%$ dos respondentes nas faixas com até 40 anos de idade. Em escolaridade, o pré-98 computou $66 \%$ de respondentes nos níveis de educação de graduação e pós-graduação. Com diferença marcante, o grupo pós-98 contabilizou 95\% nas mesmas faixas. Nas variáveis de estado civil, o pré-98, por ter participantes com idade média superior, concentrou $72,4 \%$ de casados e exíguo número de solteiros, com $13,2 \%$. A amostra do pós-98 possui distribuição inversa, com 55,5\% de solteiros e apenas 39,9\% de casados. O perfil de antiguidade de empresa da amostra pré-98, em razão da data de contratação, concentrou $87 \%$ de empregados com mais de 16 anos. Pelo mesmo motivo, no pós-98, resultou em $78,7 \%$ da amostra com até 5 anos de empresa.

A Tabela 1 apresenta dados gerais sobre as medidas dos construtos centrais da pesquisa e dos escores obtidos nas amostras participantes, discriminando-se os dois subgrupos que foram comparados quanto ao tempo de ingresso na organização.

Tabela 1. Médias e índices de alpha de Cronbach e significâncias das diferenças entre médias nas amostras integral, pré e pós-98.

\begin{tabular}{lcccccccccccc}
\hline & \multicolumn{4}{c}{} & \multicolumn{4}{c}{ Amostra integral } & \multicolumn{3}{c}{ Amostra pré-98 } & \multicolumn{4}{c}{ Amostra pós-98 } \\
\hline Dimensão & Média & Dp & Sig p & Cronb. & Média & Dp & Sig p & Cronb. & Média & Dp & Sig p & Cronb. \\
\hline Compr. afetivo & 3,70 & 0,94 & 0,00 & 0,81 & 3,91 & 0,88 & 0,00 & 0,80 & 3,52 & 0,98 & 0,00 & 0,81 \\
\hline Comp. instrumental & 3,18 & 0,82 & 0,28 & 0,68 & 3,47 & 0,83 & 0,00 & 0,69 & 2,95 & 0,82 & 0,56 & 0,67 \\
\hline Comp. normativo & 2,93 & 0,94 & 0,00 & 0,78 & 3,21 & 0,92 & 0,00 & 0,76 & 2,71 & 0,95 & 0,00 & 0,78 \\
\hline Justiça distributiva & 2,20 & 1,04 & 0,00 & 0,92 & 2,56 & 1,17 & 0,00 & 0,93 & 1,91 & 0,95 & 0,00 & 0,91 \\
\hline
\end{tabular}

Nota: Dp desvio padrão; Cronb. - alpha de Cronbach 
Na avaliação das escalas, utilizou-se o alpha de Cronbach, que visa a medir o grau de consistência interna e o nível de confiabilidade. De acordo com Cronbach (1996), valores entre 0,6 e 0,8 são considerados resultados de boa qualidade, que avalizam que as escalas são confiáveis. Os coeficientes alpha, obtidos tanto na amostra geral como nas subamostras, revelaram índices satisfatórios, conforme Tabela 1. Os escores médios revelaram predominância da dimensão afetiva, sendo esta mais expressiva na amostra pré-98. O fator instrumental emergiu como comprometimento intermediário e com maior força no grupo pré-98. Embora haja diferenças significativas entre as amostras, as médias de justiça distributiva revelam percepção baixa em todas as avaliações.

As correlações entre as dimensões de comprometimento e de justiça, apresentadas na Tabela 2, foram congruentes com os resultados dos estudos de Meyer et al. (2002) e de Rego e Souto (2004), inclusive confirmando a intensa correlação entre os tipos afetivo e normativo. Essa reiterada redundância e aposição colocam em xeque a autonomia e a distinguibilidade desses construtos. As correlações entre comprometimento e justiça distributiva também foram similares aos resultados obtidos pelos dois autores, exceto pelo fato de que a relação mais forte se deu com a dimensão normativa.

Tabela 2. Quadro comparativo das correlações entre as dimensões de comprometimento e justiça distributiva.

\begin{tabular}{|c|c|c|c|c|c|c|c|c|c|c|c|}
\hline \multirow{3}{*}{ Amostras } & \multicolumn{11}{|c|}{ Índices de correlações } \\
\hline & \multicolumn{2}{|c|}{$\begin{array}{c}\text { Afetivo x } \\
\text { instrumental }\end{array}$} & \multicolumn{2}{|c|}{$\begin{array}{c}\text { Afetivo } x \\
\text { normativo }\end{array}$} & \multicolumn{2}{|c|}{$\begin{array}{c}\text { Afetivo x } \\
\text { j. distributiva }\end{array}$} & \multicolumn{2}{|c|}{$\begin{array}{c}\text { Instrumental x } \\
\text { normativo }\end{array}$} & $\begin{array}{l}\text { Instrumental x } \\
\text { j. distributiva }\end{array}$ & \multicolumn{2}{|c|}{$\begin{array}{l}\text { Normativo } \mathrm{x} \\
\text { j. distributiva }\end{array}$} \\
\hline & Pearson & Sig. & Pearson & Sig. & Pearson & Sig. & Pearson & Sig. & Pearson Sig. & Pearson & Sig. \\
\hline Pré-98 & $-0,16$ & 0,01 & 0,54 & 0,00 & 0,31 & 0,00 & 0,12 & 0,04 & 0,02 & 0,45 & 0,00 \\
\hline Pos -98 & $-0,22$ & 0,00 & 0,56 & 0,00 & 0,38 & 0,00 & 0,00 & 0,96 & $-0,05 \quad 0,32$ & 0,42 & 0,00 \\
\hline Meyer et al., 2002 & 0,05 & - & 0,63 & - & 0,40 & - & 0,18 & - & $-0,06$ & 0,31 & - \\
\hline Rego e Souto, 2004 & $-0,16$ & 0,00 & 0,47 & 0,00 & 0,35 & 0,00 & 0,03 & 0,00 & 0,00 & 0,32 & 0,00 \\
\hline
\end{tabular}

Nota: sig. - significância; o trabalho de Meyer et al. (2002) não informou os valores de significância

O quadro de correlações, na Tabela 3, confirma a relação negativa de escolaridade com as dimensões de comprometimento e justiça. A variável idade registrou correlação positiva com as dimensões afetiva, normativa e instrumental. Com relação à justiça distributiva, a tendência é de neutralidade. Ambas as variáveis têm índice de correlação de baixa intensidade.

Tabela 3. Correlação de Pearson entre escolaridade, idade e as dimensões de comprometimento e de justiça.

\begin{tabular}{clccccccccc}
\hline & & $\mathrm{n}$ & $\mathrm{JD}$ & Sig. & $\mathrm{CN}$ & Sig & $\mathrm{Cl}$ & Sig. & $\mathrm{CA}$ & Sig. \\
\hline \multirow{2}{*}{ PRÉ-98 } & Escolaridade & 304 & $-0,12$ & 0,04 & $-0,13$ & 0,02 & $-0,02$ & 0,78 & $-0,06$ & 0,31 \\
\cline { 2 - 10 } & Idade & 304 & 0,01 & 0,94 & 0,11 & 0,06 & 0,03 & 0,56 & 0,07 & 0,20 \\
\hline \multirow{2}{*}{ PÓS-98 } & Escolaridade & 374 & $-0,12$ & 0,02 & $-0,07$ & 0,21 & $-0,03$ & 0,62 & 0,05 & 0,38 \\
\cline { 2 - 10 } & Idade & 374 & 0,29 & 0,57 & 0,06 & 0,21 & 0,09 & 0,08 & 0,07 & 0,16 \\
\hline
\end{tabular}

Nota: $\mathrm{n}$ - tamanho da amostra; JD - justiça distributiva; $\mathrm{CN}$ - comprometimento normativo; $\mathrm{Cl}$ - comprometimento instrumental; CA - comprometimento afetivo 
Para avaliar as possíveis relações das variáveis independentes escolaridade e faixa etária com as variáveis-critério comprometimento afetivo e normativo, utilizou-se a técnica de regressão simples e múltipla, método stepwise, conforme o número de variáveis envolvidas na equação. A dimensão instrumental apresentou correlações neutras, não havendo regressões a fazer. A justiça distributiva apresenta-se como variável-critério e independente, na Tabela 4.

Tabela 4. Avaliação das regressões das variáveis comprometimento afetivo, normativo e justiça distributiva.

\begin{tabular}{|c|c|c|c|c|c|c|c|c|c|c|c|c|}
\hline \multirow{3}{*}{$\begin{array}{l}\text { Variáveis } \\
\text { independentes }\end{array}$} & \multicolumn{12}{|c|}{ Variáveis dependentes - amostra pré-98 } \\
\hline & \multicolumn{4}{|c|}{ Comprometimento afetivo } & \multicolumn{4}{|c|}{ Comprometimento normativo } & \multicolumn{4}{|c|}{ Justiça distributiva } \\
\hline & B & Rs & Rsa & $\mathrm{Ee}$ & B & Rs & Rsa & $\mathrm{Ee}$ & B & Rs & Rsa & Ee \\
\hline Escolaridade & $-0,16$ & 0,03 & 0,24 & 0,84 & $-0,16$ & 0,06 & 0,02 & 0,91 & $-0,15$ & 0,02 & 0,02 & 1,11 \\
\hline Idade & 0,14 & 0,02 & 0,02 & 0,87 & 0,15 & 0,02 & 0,02 & 0,91 & & & & \\
\hline J.distributiva & 0,28 & 0,08 & 0,08 & 0,85 & 0,42 & 0,18 & 0,17 & 0,84 & & & & \\
\hline E. JD & 0,31 & 0,10 & 0,09 & 0,84 & 0,45 & 0,21 & 0,20 & 0,82 & & & & \\
\hline \multirow[t]{7}{*}{ E. Id. JD } & & & & & 0,47 & 0,22 & 0,21 & 0,82 & & & & \\
\hline & \multicolumn{12}{|c|}{ Variáveis dependentes - amostra pós-98 } \\
\hline & \multicolumn{4}{|c|}{ Comprometimento afetivo } & \multicolumn{4}{|c|}{ Comprometimento normativo } & \multicolumn{4}{|c|}{ Justiça distributiva } \\
\hline & B & Rs & Rsa & $\mathrm{Ee}$ & B & Rs & Rsa & $\mathrm{Ee}$ & B & Rs & Rsa & $\mathrm{Ee}$ \\
\hline & $-0,18$ & 0,03 & 0,26 & 0,88 & $-0,14$ & 0,02 & 0,02 & 0,89 & $-0,18$ & 0,01 & 0,01 & 0,95 \\
\hline & 0,38 & 0,15 & 0,14 & 0,91 & 0,41 & 0,17 & 0,17 & 0,87 & & & & \\
\hline & 0,40 & 0,16 & 0,15 & 0,90 & 0,43 & 0,18 & 0,18 & 0,86 & & & & \\
\hline
\end{tabular}

Nota: B - Beta; Rs - R square; Rsa - R square ajustado; Ee- erro estimado; E. JD - escolaridade e justiça distributiva; E. Id. JDescolaridade, idade e justiça distributiva

A escolaridade registrou beta negativo nas amostras pré e pós-98, indicando que, quanto mais elevado o nível educacional, menores o comprometimento afetivo, o normativo e a percepção de justiça. Seus valores de Rsa indicaram um baixo poder explicativo da variabilidade das variáveis dependentes. A variável idade exibiu beta positivo, e os valores de Rsa indicaram que há relação de baixa intensidade com os fatores afetivo e normativo. Com a justiça distributiva, a relação foi nula, e essa variável independente foi a de maior poder explicativo, apresentando relação positiva, consignando índice Rsa de $17 \%$ de explicação da variabilidade da dimensão normativa, nas amostras pré e pós-98. A junção das variáveis independentes escolaridade e justiça distributiva gerou resultado muito próximo da soma de seus Rsa. O conjunto de variáveis que entraram no modelo - escolaridade, idade e justiça distributiva - redundou em poder explicativo importante do comprometimento normativo, com o índice de $21,2 \%$ de predição na amostra pré-98. Na amostra pós-98, entraram apenas escolaridade e justiça distributiva, que explicam $18 \%$ de predição.

\section{Conclusão}

O fato novo desta pesquisa residiu na circunstância atípica do problema investigado, ou seja, a contratação de remuneração e benefícios diferenciados a dois grupos de empregados da mesma empresa, que ocupam cargo igual e desenvolvem atividades similares. Essa situação, além de inusitada em termos de mercado de trabalho, vicejou como auspiciosa oportunidade para se estudar a interação mais franca, direta e transparente de remuneração e benefícios 
sobre justiça distributiva e comprometimento organizacional.

Para a operacionalização dos objetivos visados, a amostra integral foi cindida em duas, por diferenças contratuais: o grupo pré98 e pós-98. Usualmente, os resultados das pesquisas em ciências sociais são comparados com resultados de amostras de outros estudos para avaliar eventuais afinidades e discrepâncias. Neste trabalho, sem prejuízo dessas comparações, foi possível coligir duas amostras significativas, distintas e passíveis de análise comparativa.

A amostra do grupo pré-98, em comparação com o grupo pós-98, registrou médias superiores nas três dimensões de comprometimento organizacional e de percepção justiça distributiva. De modo elucidativo, em razão das características de cada grupo, as interações diretas das variáveis antecedentes (idade, estado civil, remuneração e justiça distributiva) com as dimensões de comprometimento registraram tendência ascendente, pressionando para cima as médias do grupo pré-98, acentuando a diferença em relação ao pós-98. O mesmo ocorreu em relação à escolaridade, porém com relação inversa. A variável antiguidade, apesar de sensibilizar positivamente as dimensões afetiva e normativa, mostrou-se indiferente à instrumental. No conjunto, as diferenças das médias verificadas foram congruentes com as peculiaridades dos grupos pré e pós-98 e com as tendências das relações.

As correlações entre as dimensões de comprometimento se revelaram baixas ou neutras no cruzamento de dados: afetivo $x$ instrumental e normativo $x$ instrumental, o que confirmou que essas dimensões são autônomas e distinguíveis entre si. Já a correlação entre as dimensões afetiva e normativa foi forte, revelando significativa sobreposição ou redundância.
Um dos nós górdios que instiga a pesquisa sobre comprometimento é a natureza opaca e obscura dos limites de suas relações e interações com outras variáveis. Nesse sentido, a inovadora estratégia de separação da amostra em dois grupos com distinções e similaridades bem evidenciadas se revelou eficaz. Quando se concluiu que educação correlacionou-se negativamente com comprometimento nos grupos pré e pós-98, isso equivale a dizer que foi confirmada sua condição de antecedente em uma amostra com predominância de casados, com maior longevidade e remuneração/benefícios superiores. De igual modo, manteve o padrão de relação em outra amostra com características opostas. Os efeitos mediadores de cultura interna, ascensão profissional, características de tarefa, cobrança por resultados e estresse no trabalho foram neutralizadas, porque eram comuns aos dois grupos.

As hipóteses no 1 e no 2 não foram refutadas, pois ficou demonstrado o poder de influência de recompensa sobre as médias de comprometimento e de justiça distributiva que, segundo correlação positiva e de proporcionalidade direta, gerou médias comparativamente inferiores no grupo pós98 e superiores no pré-98. A hipótese 3 foi refutada, pois a correlação mais intensa ocorreu entre a justiça distributiva e o comprometimento normativo, dissentindo da hipótese que apontava, com base em estudos anteriores, a dimensão afetiva.

Limitações e recomendações - Frente à multiplicidade de perspectivas do problema, à diversidade de condições ambientais e às alternativas de abordagem, é impossível escoimar o trabalho das limitações e lacunas, que são inevitáveis em qualquer esforço investigativo, particularmente nas ciências sociais. Assim ocorreu com esse estudo no que alude ao levantamento dos dados em uma única empresa, de grande porte e de economia mista, configurando uma restrição, 
dentre outras, de natureza cultural, fato que limita as possibilidades de extrapolação dos resultados.

Outra restrição diz respeito à coleta de dados de diferentes construtos na mesma fonte e simultaneamente. Podsakoff e Organ (1986, como citado em Rego \& Souto, 2004) alertam para o risco dessa estratégia metodológica, de contaminação das relações entre variáveis dependentes e independentes, o que leva a dados distorcidos por raciocínio do tipo: "sinto-me justamente tratado, logo devo expressar comprometimento na mesma proporção". Para mitigar essa possível interpolação no questionário, as perguntas das dimensões de comprometimento (dependentes) antecederam as de percepção de justiça (independentes).

Sobre o baixo resultado da pergunta de justiça distributiva que inquiriu sobre equidade entre estresse e recompensa, é recomendável investigar as percepções dos empregados sobre as condições laborais e cruzar esses dados com os diagnósticos dos exames periódicos de saúde para avaliar a qualidade de vida no trabalho e subsidiar possíveis intervenções.

Ao cotejar as médias das dimensões de comprometimento obtidas neste estudo com os resultados apurados por Fonseca (2001) na mesma empresa, verificou-se uma mudança na configuração do comprometimento dos empregados, com um declínio da dimensão afetiva e concomitante ascensão da perspectiva instrumental. Entretanto, novos estudos são necessários para confirmar se esse movimento constitui uma tendência ou uma oscilação circunstancial.

Um dos fundamentos do pensamento filosófico de Heráclito de Éfeso, que viveu no século VI a.C., foi a ideia de que "tudo flui, e que a vida, mais do que objeto, é processo" (Dornelles, 2006). Nessa senda, como o desenvolvimento dos fenômenos sociais tem natureza processual, é pertinente, em futuras pesquisas sobre comprometimento, implementar abordagem longitudinal, com ênfase em análise diacrônica, para eliciar interações latentes, desvelar a dinâmica das relações, identificar curvas de tendências temporais e viabilizar alternativa de estudos de recorte pontual ou conjuntural.

Por fim, ao abordar o comprometimento e a justiça organizacional em relação à diversidade de contratos em uma mesma empresa, questão atual e candente no debate sobre as relações no trabalho, espera-se que este trabalho tenha agregado informações ao estudo desses construtos.

José Adauto Ribeiro*

Mestre em Administração, professor da Universidade Federal da Bahia, Salvador, BA - Brasil. Escola de Administração, NPGA - Núcleo de Pós-Graduação em Administração

Antônio Virgilio Bittencourt Bastos

Doutor em Psicologia, professor da Universidade Federal da Bahia, Salvador, BA - Brasil. Departamento de Psicologia. E-mail: antoniovirgiliobastos@gmail.com

*Endereço para envio de correspondência:

Rua Rio de Janeiro, 695, ap. 301, Bairro Pituba - Salvador, BA - Brasil - CEP 41830-401.

E-mail: adautoribeiro@oi.com.br 
Ansoff, H. I., McDonnell, E. J. (1993). Implantando a administração estratégica. São Paulo: Atlas.

Assmar, E. M. L., Ferreira, M. C., \& Souto, S. O. (2005). Justiça organizacional: uma revisão crítica da literatura. Psicologia: Reflexão e Crítica, 18(3), 443-453.

Bandeira, M. L., Marques, A. L., \& Veiga, R. T. (2000, maio/ agosto). As dimensões múltiplas do comprometimento organizacional: um estudo na ECT. RAC, 4, 2.

Barbosa, S. L., \& Faria J. H. (2000). Comprometimento: uma avaliação crítica sobre a práxis organizacional. In Florianópolis. In Anais do $24^{\circ}$ Encontro Anual da ANPAD, Florianópolis. Rio de Janeiro: Associação Nacional de PósGraduação e Pesquisa em Administração.

Bastos, A. V. B. (1994). O conceito de comprometimento: sua natureza e papel na explicação do comportamento humano no trabalho. In Anais do $18^{\circ}$ Encontro Anual da ANPAD Curitiba. Rio de Janeiro: Associação Nacional de PósGraduação e Pesquisa em Administração.

Becker, H. S. (1960). Notes on the concept of commitment. The American Journal of Sociology, 66, 32-40.

Blau, G. J. (1987) Using a person-environment fit model to predict job involvement and organization commitment. Journal of Vocational Psychology, 30, 240-257.

Colquitt, J. A. et al. (2001). Justice at the millennium: A metaanalytic review of 25 years of organizational justice research Journal of Applied Psychology, 86(3), 425- 445.

Coradi, C. D. (1985). O comportamento humano em administração de empresas. São Paulo: Pioneira.

Cronbach, L. J. (1996). Fundamentos da testagem psicológica (5a ed., Silveira Neto \& M. A. V. Veronese, Trads.). Porto Alegre: Artes Médicas.

Da Silva, A. M. M., Almeida, G. O., \& Carvalho, D. (2004). O papel das dimensões da justiça organizacional distributiva processual, interpessoal e informacional na predição de Burnout. Revista de Administração Mackenzie, ano 6(1), 107-127.

Dorneles, G. de S. (2006). Metagestão: a arte do diálogo nas organizações. São Paulo: Saraiva.

Drucker, P. (2006). Desafios gerenciais para o século XXI. São Paulo: Pioneira.

Fonseca, C. A. M. (2001). Criatividade e comprometimento organizacional: suas relações com a percepção de desempenho no trabalho. Dissertação de Mestrado, Escola de Administração/NPGA, Universidade Federal da Bahia, Salvador.

Gama, A. L. G. (1997). Percepção do sistema de avaliação de desempenho e o comprometimento organizacional. Dissertação de Mestrado, Universidade de Brasília, Brasília, DF.

Gomide Jr., S. (1999). Antecedentes e conseqüentes das percepções de justiça no trabalho. Tese de Doutorado, Universidade de Brasília, Brasília, DF.

Homans, G. C. (1958). Social behavior as exchange. American Journal of Sociology, 63, 597-606.
Kidron, A. (1978). Work values and organization commitment. Academy of Management Journal, 21, 239-247.

Malvezzi, S. (1994). Do taylorismo ao comportamentalismo: 90 anos de desenvolvimento de recursos humanos. Manual de $T$ $\& D$ ABTD (pp. 15-34). São Paulo: Makron Books.

Mathieu, J., \& Zajac, D. (1990). A review and meta-analysis of the antecedents, correlates, and consequences of organizational commitment. Psychological Bulletin, 108, 2, 171-194.

Medeiros, C. A. F. et al. (2002). Comprometimento organizacional: o estado da arte da pesquisa no Brasil. In Anais do $26^{\circ}$ Encontro Anual da ANPAD, Salvador. Rio de Janeiro: Associação Nacional de Pós-Graduação e Pesquisa em Administração.

Meyer, J. P., \& Allen, N. J. (1997). Commitment in the workplace: Theory, research and application. London: Sage.

Meyer, J. P. et al. (2002). Affective, continuance, and normative commitment to the organization: A meta-analysis of antecedents, correlates, and consequences. Journal of Vocational Behavior, 61, 20-52.

Mendonça, H. et al. (2004). Percepção e julgamento da retaliação organizacional: construção e validação fatorial de um instrumento. Estudos de Psicologia, 9(3), 543-551.

Mowday, R. T., Steers, R. M., \& Porter, L. W. (1979). The measurement of organizational commitment. Journal of Vocational Behavior, 14, 224-247.

Omar, Alicia. (2006). Justicia organizacional, individualismocolectivismo y estrés laboral. Psicologia y Salud, 16, 2, 207-217.

Palazolli, F. (2000, julho/setembro). Percepção de justiça nas organizações como antecedente dos comportamentos de cidadania organizacional. Caderno de Pesquisa em Administração, 7, 3.

Rawls, J. (1971). A theory of justice. Cambridge, MA: Harvard University Press.

Rego, A., \& Souto, S. (2004, janeiro/março). A percepção de justiça como antecedente do comprometimento organizacional: um estudo luso-brasileiro. $R A E, 8,1,151-177$.

Siqueira, M. M. M. (1995). Antecedente de comportamentos de cidadania organizacional: a análise de um modelo pós-cognitivo. Tese de Doutorado, Instituto de Psicologia, Universidade de Brasília, Brasília, DF.

Siqueira, M. M. M. et al. (1996). Análise de um modelo póscognitivo para a intenção de rotatividade. In Anais, 26 Congresso Interamericano de Psicologia, São Paulo. São Paulo: CIP.

Tamayo, A., Souza, M. G. S., Vilar, L. S, Ramos, J. L., Albernaz, J. V., \& Ferreira, N. P. (2001). Prioridades axiológicas e comprometimento organizacional. Psicologia: Teoria e Pesquisa, 17(1), 27-35.

Vroom, V. H. (Orgs.). (1997). Gestão de pessoas, não de pessoal - os melhores métodos de motivação e avaliação de desempenho. Rio de Janeiro: Campus.

Wiener, Y. (1982). Commitment in organizations: A normative view. Academy of Management Review, 7, 418-428. 